\title{
Mechanical Properties of Some Metallic Powder Alloys and Their Contribution to the Performance of Diamond Tools Used for Cutting Granite
}

\author{
Luís Guerra Rosa *(i), Carlos A. Anjinho, Pedro M. Amaral ${ }^{(\mathbb{D}}$ and Jorge Cruz Fernandes $\mathbb{(}$ \\ IDMEC, DEM, Instituto Superior Técnico, Universidade de Lisboa, 1049-001 Lisboa, Portugal; \\ gancho.anjinho@gmail.com (C.A.A.); Pedro.Amaral@tecnico.ulisboa.pt (P.M.A.); \\ cruz.fernandes@tecnico.ulisboa.pt (J.C.F.) \\ * Correspondence: luisguerra@tecnico.ulisboa.pt; Tel.: +351-21-841-7280
}

Received: 29 October 2019; Accepted: 11 November 2019; Published: 13 November 2019

\begin{abstract}
This work examined some pre-alloyed cobalt-, iron-, and copper-based powder binder systems-such as those launched commercially under the brand names of Cobalite and Next-in terms of their as-sintered physical-mechanical properties, namely, apparent density, Young's modulus, yield strength, rupture strength, rupture strain, toughness modulus, and Vickers hardness. These types of sintered products are traditionally used in the fabrication of diamond impregnated tools for cutting granite stones. The following powder binder systems were evaluated: Cobalite HDR pre-alloyed powder, Next 300 pre-alloyed powder, and four other mixtures of these with $\mathrm{Cu}$ and $\mathrm{Fe}$ powders: Cobalite HDR $+20 \mathrm{wt} \% \mathrm{Cu}$; Cobalite HDR $+20 \mathrm{wt} \% \mathrm{Fe}$; Next $300+20 \mathrm{wt} \% \mathrm{Cu}$; Next $300+$ $20 \mathrm{wt} \%$ Fe. The evaluation methodology aimed to establish criteria for developing new diamond tools and, therefore, it included the measurement of several technological parameters directly related to the cutting performance of the tools (e.g., energy consumption measurements made exclusively in the tool drive motor, forces generated in the tool, tool consumption per unit weight of stone removed by the cutting). The results show the adequacy of the methodology for the optimisation of diamond retention capacity of these types of metal matrices and for improving the working performance of the diamond tools.
\end{abstract}

Keywords: cobalt-based alloy; pre-alloyed agglomerates; hot pressed sintering; mechanical properties; cutting performance; diamond impregnated tools; stone machining; tool wear

\section{Introduction}

Sintered powder metallurgy (PM) products are traditionally used in the fabrication of diamond impregnated tools (usually named "diamond tools" for short) for cutting natural stone or other hard materials, such as concrete or artificial stones. A huge variety of different types of petrous materials is used nowadays in architecture and sculpture. Compared to metal alloys, petrous materials (natural or man-made) usually show a more heterogeneous microstructure, and they can be much more difficult for machining (e.g., drilling, sawing, grinding, or polishing) in order to obtain the final shape. Depending on the hardness of their mineralogical constituents, some petrous materials are more difficult to cut than others, and therefore the concept of "relative abrasiveness" was introduced in a publication dated 1998, and therein [1] a method for the classification of ornamental stones according to the abrasiveness that they show during a processing operation, involving the removal of stock material by a tool, was presented.

It is due to their higher efficiency and longer service life that diamond tools are used for most stages of the machining process. For each type of stone and each stage of the machining process 
there will be an optimum tool, and therefore, in order to satisfy their costumers, tool manufacturers continuously provide the market with new and more efficient diamond tools $[2,3]$.

In fact, the abrasiveness of petrous materials can be very severe and manufacturers of diamond tools are aware of that and make use of many types of commercially available metal powders which, after a consolidation process, play the role of "binders for diamond". The role of the binders is crucial for the performance of the diamond tools [4]. There are already several works dealing with the simulation by computer modelling of the retention of a synthetic diamond particle in a metallic matrix, e.g., [5-9], and there are other type of works aiming to understand the wear of materials with granitic textures (e.g., granite, granodiorite, gabbro, quartzite) while being processed by diamond tools $[10,11]$.

Based on our own experience, the present work intends to demonstrate the experimental methodologies that can be used to assess the properties that are thought to be the most relevant ones in terms of the metallic binders. Our previous investigations $[12,13]$ have shown that the wear of the PM matrices can be related to the resultant force $\left(F_{r}\right)$ applied to the tool and with some mechanical properties of the PM matrix through the following empirical expression:

$$
\Delta m=\alpha \cdot \frac{F_{r}}{\sigma_{r}^{0.6} \cdot T_{m}^{0.1} \cdot H_{V}^{0.5} \cdot E}
$$

where $\Delta m$ represents the matrix weight loss (per run of the tool), $\alpha$ is a constant of proportionality, $\sigma_{r}$ is the rupture strength (ultimate tensile stress), $T_{m}$ is the modulus of toughness, $H_{V}$ is the Vickers hardness, and $E$ is the Young's modulus.

Once the properties of different PM binders are determined after sintering, the tool manufacturer can then make decisions in order to produce the diamond tools using the selected binders. The way in which diamond tools can then afterwards be adequately tested under real industrial conditions is also presented in this work.

\section{Materials and Methods}

\subsection{Starting Powders}

Information on the starting powders is given in Table 1. Table 2 summarizes the chemical compositions of the PM mixtures studied in this work, which were: the Cobalite HDR pre-alloyed powder, the Next 300 pre-alloyed powder, and four other mixtures of these with copper or iron powders. Values of theoretical or maximum achievable density corresponding to a fully densified body are also shown in Table 2. The reason for adding $\mathrm{Cu}$ and Fe to the Cobalite and Next compositions was to investigate the influence of those additions in terms of change in microstructure and physical-mechanical properties. Depending on the type of tool and on the type of stone to be machined, manufacturers of diamond tools for stone processing also use these compositions with a higher content of $\mathrm{Cu}$ or higher content of Fe. For example, and just for clarification, the mixture named "Cobalite HDR $+20 \% \mathrm{Cu}$ " in Table 2 consists of $20 \%$ pure $\mathrm{Cu}$ powder and $80 \%$ Cobalite HDR powder.

Table 1. Starting powders.

\begin{tabular}{ccc}
\hline Powders Designation & Fisher Sub-Sieve Size $(\boldsymbol{\mu m})$ & Supplier \\
\hline Cobalite HDR & $6-7$ & Umicore \\
Next 300 & $\sim 4$ & Eurotungstene \\
Electrolytic Cu & $11-12$ & Eurotungstene \\
Carbonyl Iron $(>99.5 \% \mathrm{Fe})$ & $7-8$ & Eurotungstene \\
\hline
\end{tabular}

According to the literature, the maximum density achievable with Cobalite HDR is $8.18 \mathrm{~g} / \mathrm{cm}^{3}$ [14] and with Next 300 is $8.12 \mathrm{~g} / \mathrm{cm}^{3}$ [15]. Once the percentages indicated in Table 2 are in weight, it is more appropriate to calculate the theoretical density values of the other powder combinations using an inverse rule of mixtures, and considering that the theoretical densities of copper and iron are $8.96 \mathrm{~g} / \mathrm{cm}^{3}$ 
and $7.87 \mathrm{~g} / \mathrm{cm}^{3}$, respectively. Then, for example, the theoretical density of the mixture Cobalite HDR + $20 \% \mathrm{Cu}$ is given by the inverse of the sum of $(0.8 /$ theoretical density of Cobalite HDR $)+(0.2 /$ theoretical density of Copper).

Table 2. Chemical composition and theoretical density of the powder metallurgy (PM) mixtures.

\begin{tabular}{|c|c|c|c|c|}
\hline \multirow{2}{*}{ Powders } & \multicolumn{3}{|c|}{ Weight Percentage } & \multirow{2}{*}{$\begin{array}{c}\text { Theoretical } \\
\text { Density }\left(\mathrm{g} / \mathrm{cm}^{3}\right)\end{array}$} \\
\hline & Co & $\mathrm{Cu}$ & $\mathrm{Fe}$ & \\
\hline Cobalite HDR & 27 & 7 & 66 & 8.18 \\
\hline Cobalite HDR + 20\% Cu & 21 & 26 & 53 & 8.33 \\
\hline Cobalite HDR $+20 \% \mathrm{Fe}$ & 21 & 6 & 73 & 8.12 \\
\hline Next 300 & 25 & 3 & 72 & 8.12 \\
\hline Next $300+20 \% \mathrm{Cu}$ & 20 & 22 & 58 & 8.28 \\
\hline Next $300+20 \% \mathrm{Fe}$ & 20 & 2 & 78 & 8.07 \\
\hline
\end{tabular}

Powders were observed with an analytical scanning electron microscope (SEM, Hitachi S-2400, Japan) and examples of the SEM observations are depicted in Figure 1.

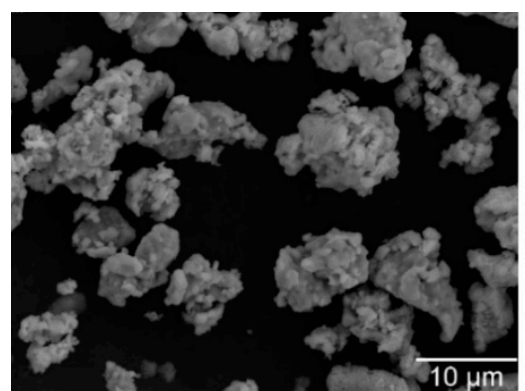

(a)

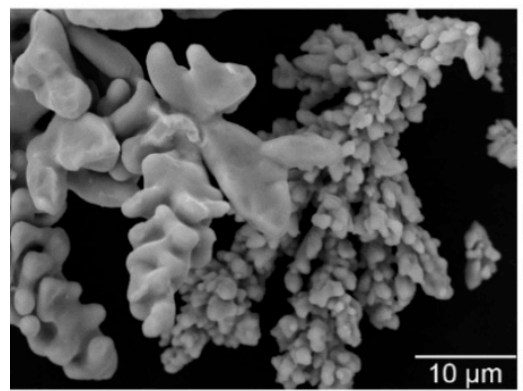

(c)

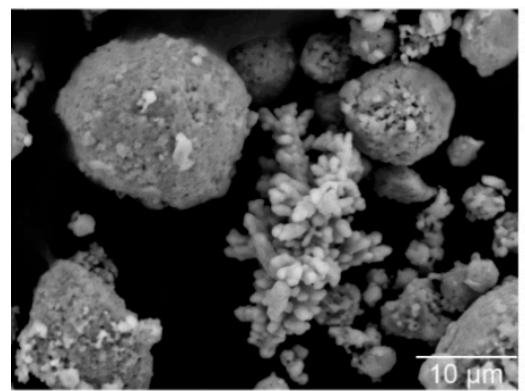

(e)

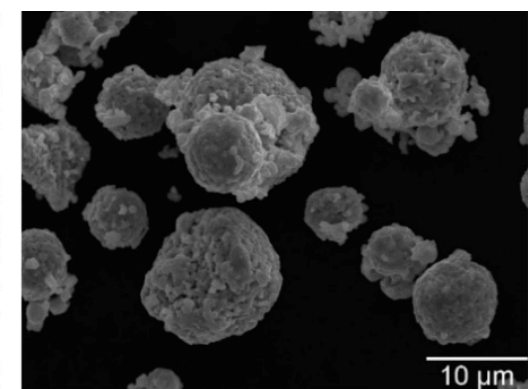

(b)

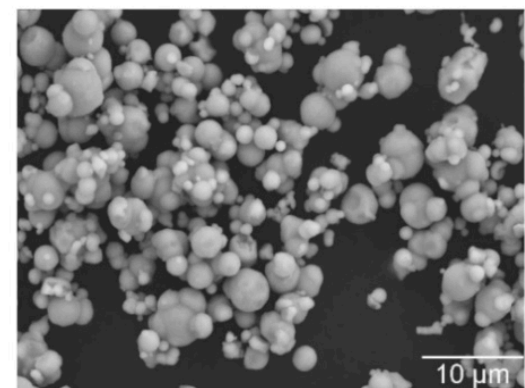

(d)

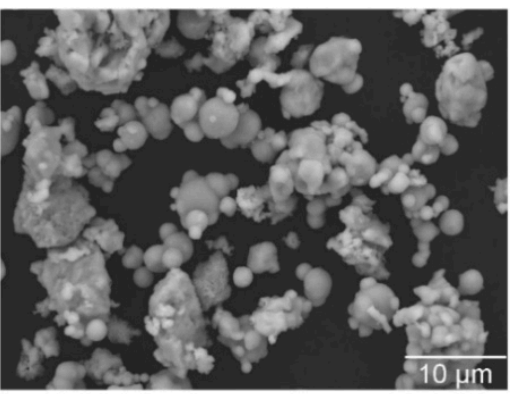

(f)

Figure 1. Scanning electron microscope (SEM) images of the starting powders: (a) Cobalite HDR powder; (b) Next 300 powder; (c) Cu powder; (d) Fe powder; (e) Cobalite HDR + 20\% Cu; (f) Next 300 $+20 \%$ Fe. 


\subsection{Sintering of Metallic Binders}

All powder mixtures were hot-pressed using graphite moulds and applying a uniaxial pressure of $33 \mathrm{MPa}$ at a sintering temperature of $800^{\circ} \mathrm{C}$. The sintered bodies (no diamonds were involved) were rectangular prisms with final dimensions of $55 \times 11 \times 10 \mathrm{~mm}^{3}$ and were obtained in groups of six. Due to the electric current applied to the graphite mould, a sufficiently high heating rate was used to make it possible to go from room temperature to $800{ }^{\circ} \mathrm{C}$ in $3 \mathrm{~min}$. Then, the holding time at $800{ }^{\circ} \mathrm{C}$ was also $3 \mathrm{~min}$. At high temperature, a reducing atmosphere containing $\mathrm{CO}$ and $\mathrm{CO}_{2}$ was generated inside the mould due to the reaction of the oxygen in the air with the graphite (carbon). This $\mathrm{CO}$ and $\mathrm{CO}_{2}$-rich atmosphere protected the powders from oxidation. Figure 2a shows one of the sintered bodies, from which the specimens used for tensile testing were machined.

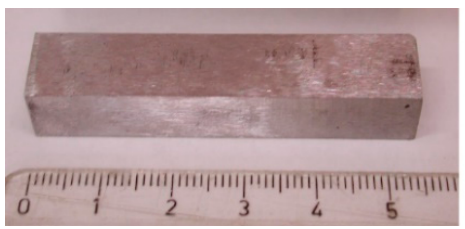

(a)

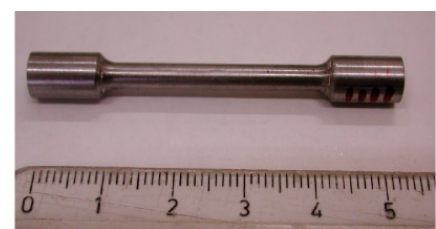

(b)

Figure 2. (a) Sintered body with dimensions of $55 \times 11 \times 10 \mathrm{~mm}^{3}$; (b) specimen used for tensile test.

The PM sintered bodies were observed by optical microscopy (OM) using an Olympus BX51M optical microscope; examples of the observations are depicted in Figure 3.

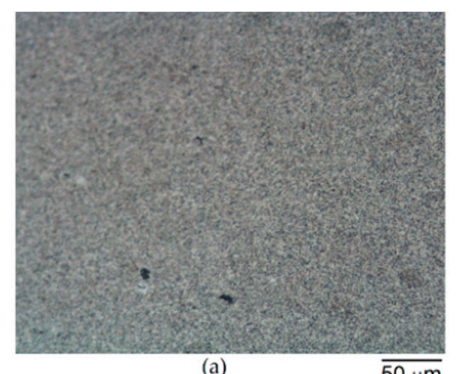

(a)

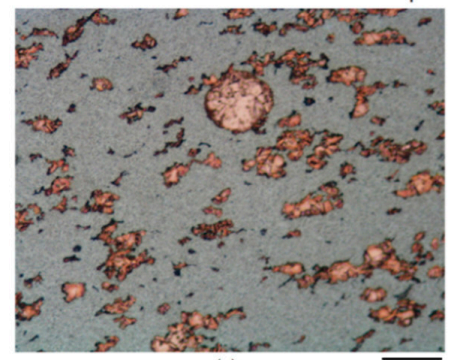

(c)

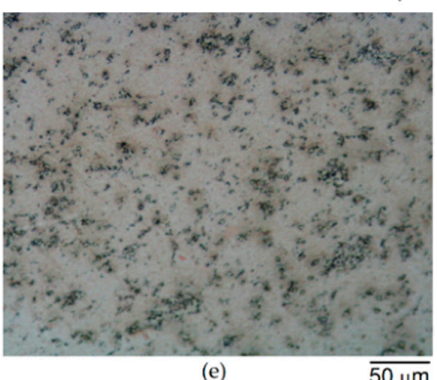

(e)
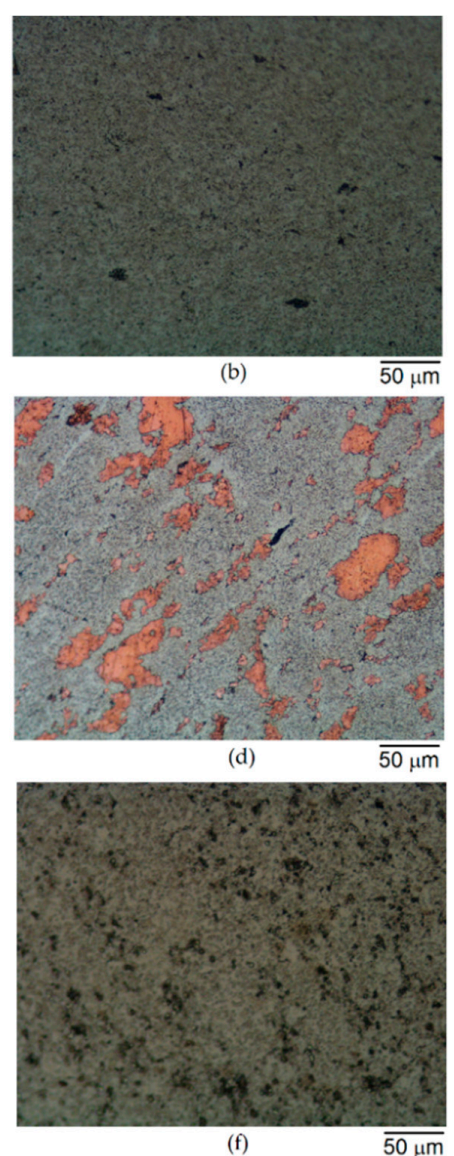

Figure 3. Optical observation of the microstructures of PM sintered bodies: (a) Cobalite HDR; (b) Next 300; (c) Cobalite HDR + 20\% Cu; (d) Next $300+20 \% \mathrm{Cu}$; (e) Cobalite HDR + 20\% Fe; (f) Next $300+$ $20 \% \mathrm{Fe}$. 
Besides optical microscopy, PM sintered bodies were also observed by SEM. Examples of those observations are shown in Figure 4. It must be clarified that, from our observations by OM and SEM, we did not notice any problem of binding between the $\mathrm{Cu}$ or Fe particles and the Cobalite HDR or Next 300 matrices.
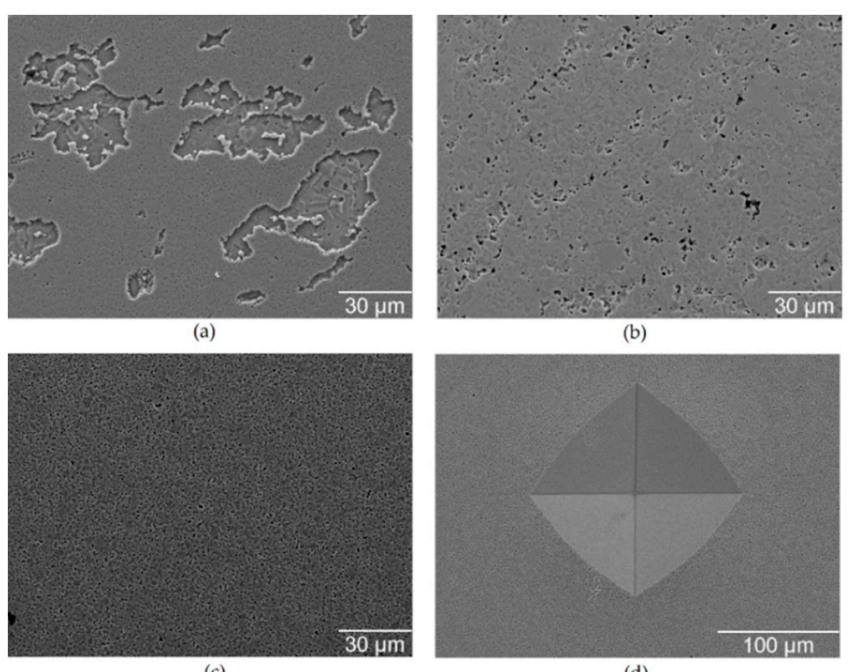

Figure 4. SEM observations of the microstructures of PM sintered bodies: (a) Cobalite HDR $+20 \% \mathrm{Cu}$; (b) Next $300+20 \%$ Fe; (c) Cobalite HDR; (d) Vickers indentation in Cobalite HDR.

\subsection{Characterisation of Metallic Binders}

Physical-mechanical characterisation of the metallic binders was carried out by determining several properties. Table 3 presents the list of properties that were determined, as well as the corresponding methodology, equipment, and total number of specimens that were used for their determination.

Table 3. Properties, methodologies, equipment, and number of specimens.

\begin{tabular}{|c|c|c|c|}
\hline Property & Methodology & Equipment & $\begin{array}{l}\text { No. of Specimens for } \\
\text { Each Type of Binder }\end{array}$ \\
\hline Apparent density & $\begin{array}{l}\text { Water immersion } \\
\text { technique }\end{array}$ & $\begin{array}{c}\text { Electronic Densimeter } \\
\text { EW-200SG }\end{array}$ & 4 \\
\hline Vickers hardness & Indentation test & $\begin{array}{c}\text { Mitutoyo AVK-C2 } \\
\text { hardness tester (using a } \\
\text { load of } 1 \mathrm{kgf} \text { ) }\end{array}$ & 3 \\
\hline Dynamic Young's modulus & Resonance frequency & $\begin{array}{l}\text { RFDA from IMCE (see } \\
\text { Figure 5) }\end{array}$ & 3 \\
\hline $\begin{array}{l}\text { Yield strength, Rupture } \\
\text { strength, Strain at rupture, } \\
\text { Modulus of toughness }\end{array}$ & $\begin{array}{l}\text { Stress-strain curves from } \\
\text { tensile tests }{ }^{1} \text { on } \\
\text { cylindrical specimens }\end{array}$ & Instron model 8502 & 3 \\
\hline
\end{tabular}

${ }^{1}$ Crosshead speed: $0.5 \mathrm{~mm} / \mathrm{min}$. 


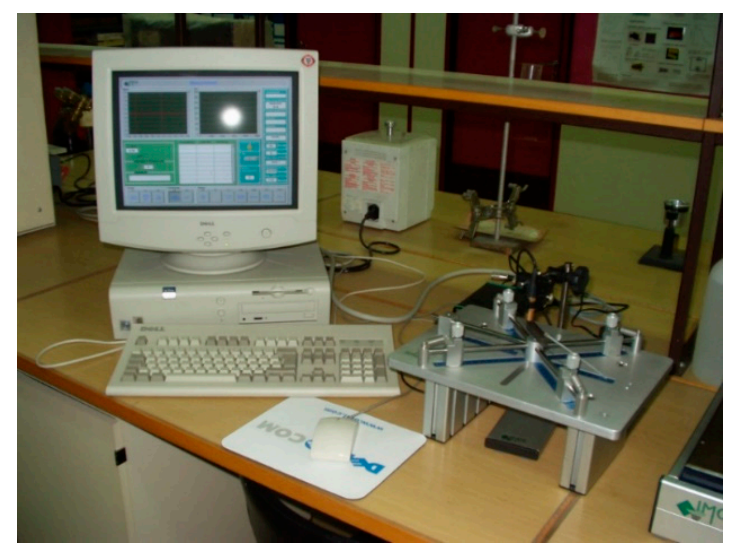

Figure 5. RFDA (Resonant Frequency and Damping Analyser) equipment (made by IMCE, Genk, Belgium) used for measuring the dynamic Young's modulus.

In addition to measurements of important properties, like apparent density, Vickers hardness, and dynamic Young's modulus, tensile tests were conducted in cylindrical specimens using an Instron strain gauge extensometer (Instron, Norwood, MA, USA), 25 mm gauge, $+100-10 \%$ max strain. The tensile tests allowed the determination of yield strength a $0.2 \%$ offset, $\sigma_{0.2}$, and also of: rupture strength (ultimate tensile stress),

$$
\sigma_{r}=\frac{F_{\max }}{A_{o}}
$$

strain at rupture,

$$
\varepsilon_{r}=\frac{L_{f}-L_{o}}{L_{o}} \times 100 \%
$$

modulus of toughness,

$$
T_{m}=\frac{\sigma_{0.2}+\sigma_{r}}{2} \varepsilon_{r}
$$

where $F_{\max }$ is the maximum force, $A_{o}$ is the initial cross-section area of the specimen, $L_{f}$ is the distance between the reference points of the specimens at the moment of rupture, and $L_{o}$ is the initial distance between those points or gauge length. The modulus of toughness is the amount of strain energy per unit volume (i.e., strain energy density) that a material can absorb just before it fractures. The modulus of toughness is calculated as the area under the stress-strain curve up to the fracture point, and for simplification purposes Equation (4) was used as an approximation.

\subsection{Characterisation of Diamond Tools}

\subsubsection{Type of Diamond Tools}

Figure 6 shows the types of tools used in this study. This type of disc is typically used in the industry for grinding granite and other hard stones. Each grinding wheel was composed of 16 diamond-impregnated segments; each segment was $24 \mathrm{~mm}$ long, $20 \mathrm{~mm}$ wide, and was initially $5 \mathrm{~mm}$ thick. The steel disc to which the segments were brazed had an external diameter of $150 \mathrm{~mm}$ and a thickness of $18 \mathrm{~mm}$. 

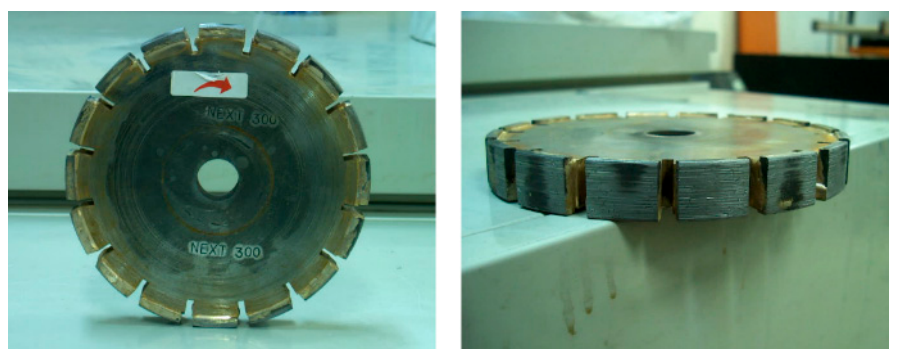

Figure 6. Type of grinding wheel used in this study.

For easier comparison of their performance, the grinding wheels were manufactured so that the only difference between them was the binder that held the diamonds. The concentration and grit of the diamond was kept constant. The diamonds were MBS 940 produced by General Electric, $40-50$ mesh size. The content of diamonds in the segments was $2.5 \mathrm{wt} \%$. The segments for the grinding wheels of Cobalite HDR and Next 300 were obtained using the same hot-pressing processing variables indicated in Section 2.2, with the only difference in the size of the graphite mould used.

\subsubsection{Stone Samples}

The granite used for evaluating the performance of the grinding wheels was from Portalegre district, Portugal, and it is commercially sold under the designation of SPI or Azul Alpalhão. Each stone tile had dimensions of $300 \times 300 \times 20 \mathrm{~mm}^{3}$. The apparent density of the Azul Alpalhão granite was $2.66 \mathrm{~g} / \mathrm{cm}^{3}$ and it was determined according to test standard EN 1936:2008.

\subsubsection{Test Procedure}

The grinding tests were carried out with the IST-Lisbon Classification Equipment (see Figure 7). The first version of this equipment was commissioned in 1997, but since then new versions have been constructed. Detailed description of the IST-Lisbon Classification Equipment can be found in other publications [16-18] and the measurements made with it allow the determination of the following parameters: the parameter $Z$ representing the electric energy consumption per unit mass of removed stone; the parameter $\phi$, which represents the mass loss of the tool per unit mass of removed stone; the force $F_{v}$, defined as the mean value of vertical load measurements monitored (and data stored) during the grinding operation; the force $F_{h}$, defined as the mean value of horizontal load measurements monitored (and data stored) during the grinding operation.

Using the abovementioned parameters it is then possible to obtain two other quantities: (i) the stone "relative abrasiveness" towards the used tool, expressed by the parameter $A$ so that:

$$
A=\mathrm{Z} \times \phi,
$$

and (ii) the resultant force $F_{r}$, generated by the contact between the tool and the granite, which is given by:

$$
F_{r}=\sqrt{F_{v}^{2}+F_{h}^{2}}
$$




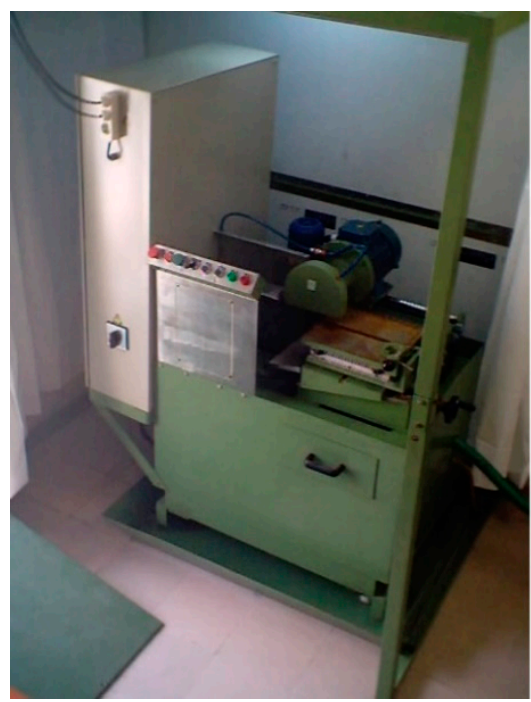

(a)

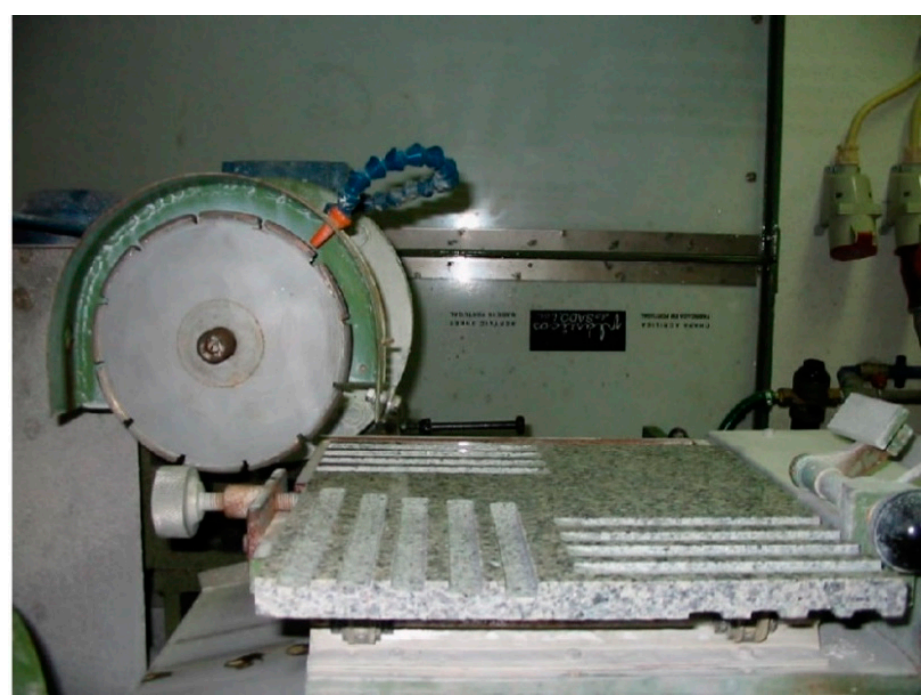

(b)

Figure 7. (a) General view of the IST-Lisbon Classification Equipment; (b) detail of a grinding test, showing several grooves made at the surface of a granite tile.

To allow the comparison of results obtained from several tools, the worktable velocity and the rotational speed of the tool, as well as the water flow, were kept constant during the tests (see Table 4). The tests were conducted with the discs rotating in downcut conditions [18] towards the tile of the granite.

Table 4. Working parameters of downcut conditions used in the tests.

\begin{tabular}{cccc}
\hline Rotational Speed & Worktable Velocity & Depth of Cut & Water Flow \\
\hline $1500 \mathrm{rpm}$ & $10 \mathrm{~mm} / \mathrm{s}$ & $3 \mathrm{~mm}$ & $1 \mathrm{~L} / \mathrm{min}$ \\
\hline
\end{tabular}

Each grinding slot or groove took $18 \mathrm{~s}$ to be made. A total of 32 grinding slots were made in each stone tile, i.e., 16 in each side of the tile (see Figure 8), and 7 tiles were used for evaluating each diamond tool. Therefore, the grinding tests comprised the removal of a considerable amount of granite (approximately $6.4 \mathrm{~kg}$ of granite per tool). Nonetheless, prior to the tests the tools were sharpened till stable cutting conditions were attained. The sharpening and conditioning procedure was conducted by observing the evolution of the segment's contact surface.

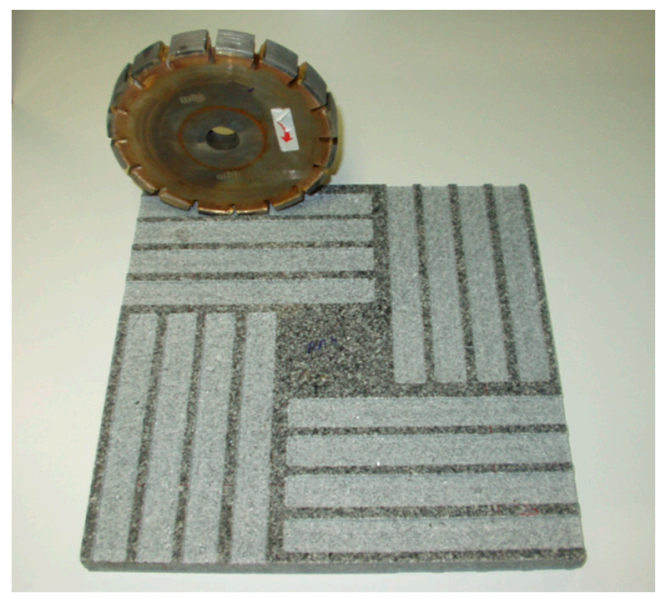

Figure 8. Sixteen grinding slots or grooves in one side of an Azul Alpalhão granite tile. 


\section{Results}

\subsection{Physical-Mechanical Properties of the Metallic Binders}

The results of apparent density determined in the different binders are summarized in Table 5. The corresponding values of porosity (also indicated in Table 5) were calculated from the equation:

$$
\% \text { porosity }=\left(1-\frac{\rho_{a}}{\rho_{t}}\right) \times 100 \%,
$$

where $\rho_{a}$ represents the apparent density and $\rho_{t}$ is the theoretical density (indicated in Table 2).

Table 5. Mean values ( \pm standard deviation) of apparent density and porosity.

\begin{tabular}{ccccccc}
\hline Property & $\begin{array}{c}\text { Cobalite } \\
\text { HDR }\end{array}$ & $\begin{array}{c}\text { Cobalite HDR }+ \\
\mathbf{2 0} \% \mathbf{C u}\end{array}$ & $\begin{array}{c}\text { Cobalite HDR }+ \\
\mathbf{2 0} \% \mathbf{~ F e}\end{array}$ & Next 300 & $\begin{array}{c}\text { Next 300 + } \\
\mathbf{2 0} \% \mathbf{C u}\end{array}$ & $\begin{array}{c}\text { Next 300 + } \\
\mathbf{2 0} \% \mathbf{F e}\end{array}$ \\
\hline $\begin{array}{c}\text { Apparent density } \\
\left(\mathrm{g} / \mathrm{cm}^{3}\right)\end{array}$ & $7.97 \pm 0.05$ & $8.16 \pm 0.03$ & $7.91 \pm 0.02$ & $7.78 \pm 0.05$ & $8.10 \pm 0.02$ & $7.80 \pm 0.06$ \\
Porosity $(\%)$ & $2.6 \pm 0.6$ & $2.2 \pm 0.4$ & $2.6 \pm 0.3$ & $4.2 \pm 0.6$ & $2.3 \pm 0.2$ & $3.3 \pm 0.8$ \\
\hline
\end{tabular}

Figure 9a gives a graphical comparison of values of apparent density and values of theoretical density, whereas Figure $9 \mathrm{~b}$ shows the values of porosity.

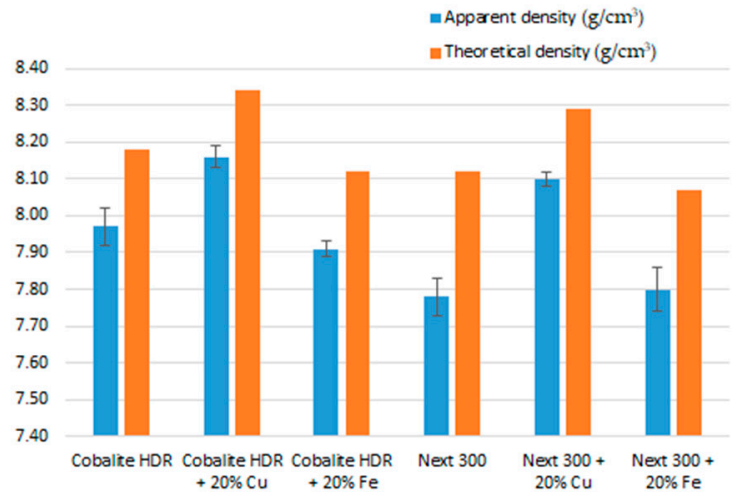

(a)

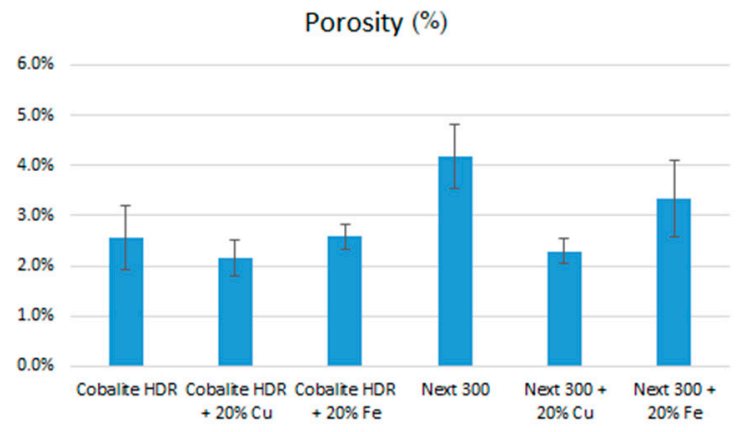

(b)

Figure 9. (a) Comparison of values of apparent and theoretical density; (b) values of porosity.

The results characterising the mechanical behaviour, obtained from Vickers hardness tests, resonance frequency analyses, and stress-strain curves from tensile tests, are summarized in Table 6 and plotted in the graphs presented in Figure 10.

Table 6. Mean values ( \pm standard deviation) of mechanical properties.

\begin{tabular}{|c|c|c|c|c|c|c|}
\hline & $\begin{array}{l}\text { Cobalite } \\
\text { HDR }\end{array}$ & $\begin{array}{l}\text { Cobalite HDR } \\
+20 \% \mathrm{Cu}\end{array}$ & $\begin{array}{c}\text { Cobalite HDR } \\
+20 \% \mathrm{Fe}\end{array}$ & Next 300 & $\begin{array}{c}\text { Next } 300+ \\
20 \% \mathrm{Cu}\end{array}$ & $\begin{array}{c}\text { Next } 300+ \\
20 \% \mathrm{Fe}\end{array}$ \\
\hline Vickers hardness $\left(\mathrm{kg} / \mathrm{mm}^{2}\right)$ & $304 \pm 5$ & $251 \pm 3$ & $262 \pm 4$ & $233 \pm 4$ & $201 \pm 6$ & $221 \pm 3$ \\
\hline Yield strength (MPa) & $1000 \pm 15$ & $750 \pm 15$ & $736 \pm 22$ & $612 \pm 12$ & $549 \pm 33$ & $531 \pm 16$ \\
\hline Rupture strength (MPa) & $1012 \pm 6$ & $759 \pm 12$ & $747 \pm 16$ & $690 \pm 24$ & $663 \pm 56$ & $616 \pm 9$ \\
\hline Strain at rupture $(\%)$ & $7.3 \pm 0.8$ & $3.2 \pm 1.1$ & $6.9 \pm 0.9$ & $19.3 \pm 3.8$ & $12.3 \pm 4.1$ & $21.0 \pm 1.6$ \\
\hline
\end{tabular}



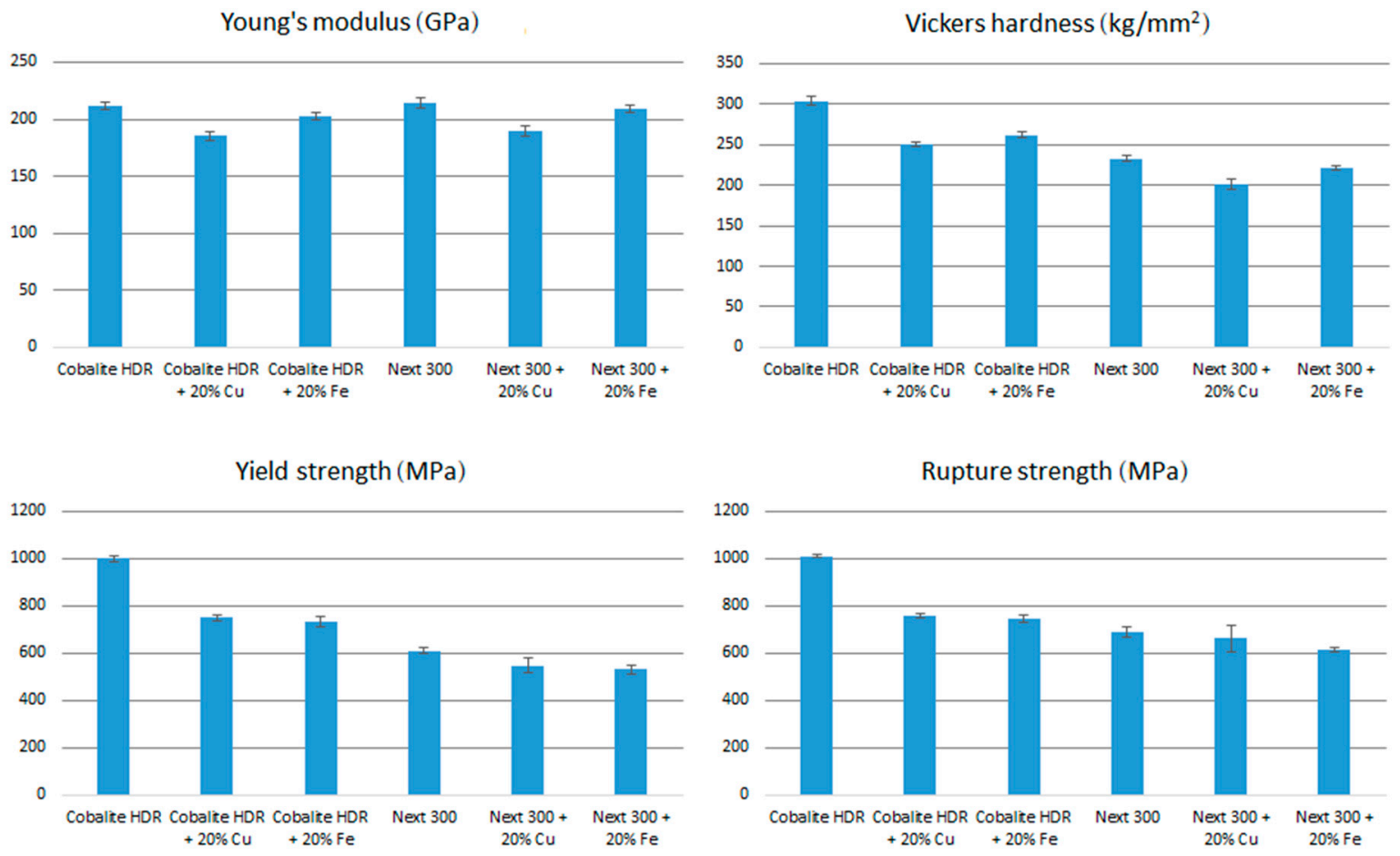

Strain at rupture $(\%)$

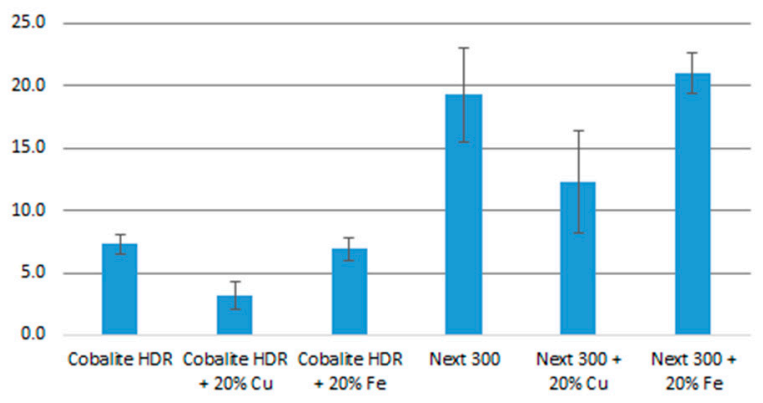

Toughness modulus $\left(\mathrm{MJ} / \mathrm{m}^{3}\right)$

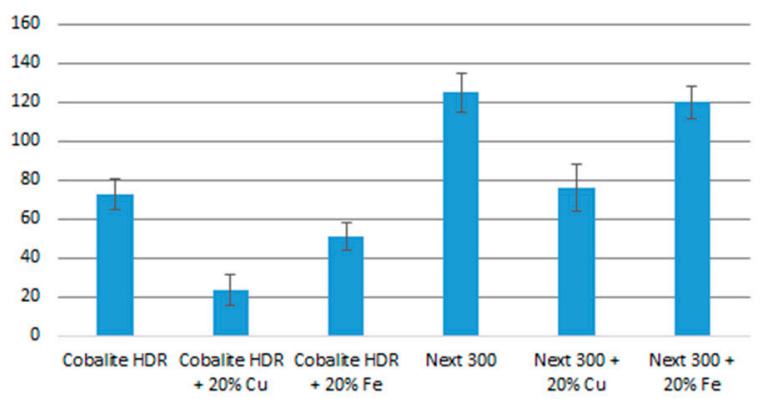

Figure 10. Results characterising the mechanical behaviour.

\subsection{Comparison Between Two Diamond Tools}

From the six different PM binders, we selected just two of them to produce the diamond tools in order to carry out grinding tests. The selection was made by applying Equation (1) and using the values the mechanical properties indicated therein (i.e., rupture strength, modulus of toughness, Vickers hardness, Young's modulus), which were determined experimentally for the six PM binders. The two PM binders/matrices showing the lowest values of matrix weight loss $(\Delta m)$ were Cobalite HDR and Next 300.

Table 7 condenses the median values of $F_{r}, \mathrm{Z}, \phi$, and $A$ obtained from tests carried out with the IST-Lisbon Classification Equipment applying the methodology described in Section 2.4.3.

Table 7. Comparison between the diamond tools with Cobalite HDR and Next 300.

\begin{tabular}{ccc}
\hline Parameter & Cobalite HDR & Next 300 \\
\hline$F_{r}(\mathrm{~N})$ & 195.9 & 218.2 \\
$\mathrm{Z}(\mathrm{J} / \mathrm{g})$ & 483.8 & 488.5 \\
$\phi(\mathrm{g} / \mathrm{g})$ & $384.3 \times 10^{-6}$ & $278.2 \times 10^{-6}$ \\
$A(\mathrm{~J} / \mathrm{g})$ & 0.186 & 0.136 \\
\hline
\end{tabular}




\section{Discussion}

After characterisation of the metallic binders, those that were considered the most suitable ones were used to produced grinding wheels geometrically equal but different in the type of metallic binder (using powders Cobalite HDR and Next 300). It is worth emphasising that the values shown in Table 7 are a consequence of long-term grinding tests, which comprised the removal of a considerable amount of granite (6.4 kg of granite per tool). The tests carried out on the two grinding wheels that were manufactured in this work showed that both of them are very efficient, and their wear rate is very low. For example, after removing 6.4 kilograms of granite, the grinding wheel with Cobalite HDR segments only lost 2.5 grams (i.e., $6400 \mathrm{~g} \times 384.3 \times 10^{-6} \mathrm{~g} / \mathrm{g}$ ) and reduction in tool diameter during the grinding test was practically unnoticeable, with $\phi$-values determined by measuring differences in the weight of the tool.

From the results presented in Table 7 one can observe that the difference in Z-values shown by Cobalite HDR and Next 300 segments were very small. The grinding wheels composed by segments made of Cobalite HDR generated lower force $\left(F_{r}\right)$ and even showed a slightly lower electric energy consumption per unit mass of removed stone $(Z)$ in comparison to the grinding wheels made with Next 300 segments. On the contrary, Cobalite HDR segments showed much higher values of $\phi$, i.e., mass loss of the tool per unit mass of removed stone. The conjunction of these different trends meant that the relative abrasiveness (parameter $A$ ) of Azul Alpalhão granite became higher when Cobalite HDR segments were employed.

The performance of the grinding wheels can be related to the mechanical properties of the metallic binders. Cobalite HDR segments (which generated lower contact force $F_{r}$ ) showed higher values of rupture strength, yield strength, and Vickers hardness, but lower values of toughness and strain at rupture. Metallic binders showing better diamond retention capacity and lower wear are supposed to be those with sufficient toughness. After the grinding tests, the segments were analysed by optical microscopy (see some photos in Figure 11) and from such inspection some conclusions were drawn. Diamonds with dark colour in the photos are those that were not yet active in the cutting process. Some diamonds only become totally active when they fracture. The tails in the metallic matrix have an important role in the process because they support the diamond when it cuts the stone. It is worth noting that the photos of Cobalite HDR segments are globally more yellowish compared to Next 300 segments, which means that Cobalite HDR segments had more active diamonds. This conclusion was confirmed by other type of observations, in which replicas of the segment surface were obtained and then analysed at the microscope. There was a higher concentration of active diamonds at the Cobalite HDR segments.

The grinding tests were conducted by imposing the depth of cut ( $3 \mathrm{~mm}$ in a single run) and, in our opinion, the complexity of the wear mechanism (involving multiple contact points between granite constituents, diamond particles, and metallic matrix) can only be adequately assessed if based on experimental evidence rather than on theoretical models. It is also important to consider the influence of the type of granite that is being cut. Since the resultant forces were higher in Next 300 segments (where a lower concentration of active diamonds was observed compared to the Cobalite HDR segments), it can be concluded that a higher concentration of active diamonds generates lower force during the cutting process. Previous studies conducted with different tools and different stone materials $[17,18]$ have shown that the electric energy consumption varies linearly with the resultant force $F_{r}$. In the present study, lower average force $F_{r}$ in the Cobalite HDR segments was accompanied by a slightly lower value of $Z$ (see Table 7).

In fact, an earlier investigation [19] confirmed the abovementioned rationale, i.e., a higher concentration of active diamonds promotes lower forces and vice-versa. One of the objectives of that earlier study [19] consisted of comparing the forces generated when a totally new segment, without active diamonds, starts to be used, with the forces generated by a similar segment that was already used and had many active diamonds. 

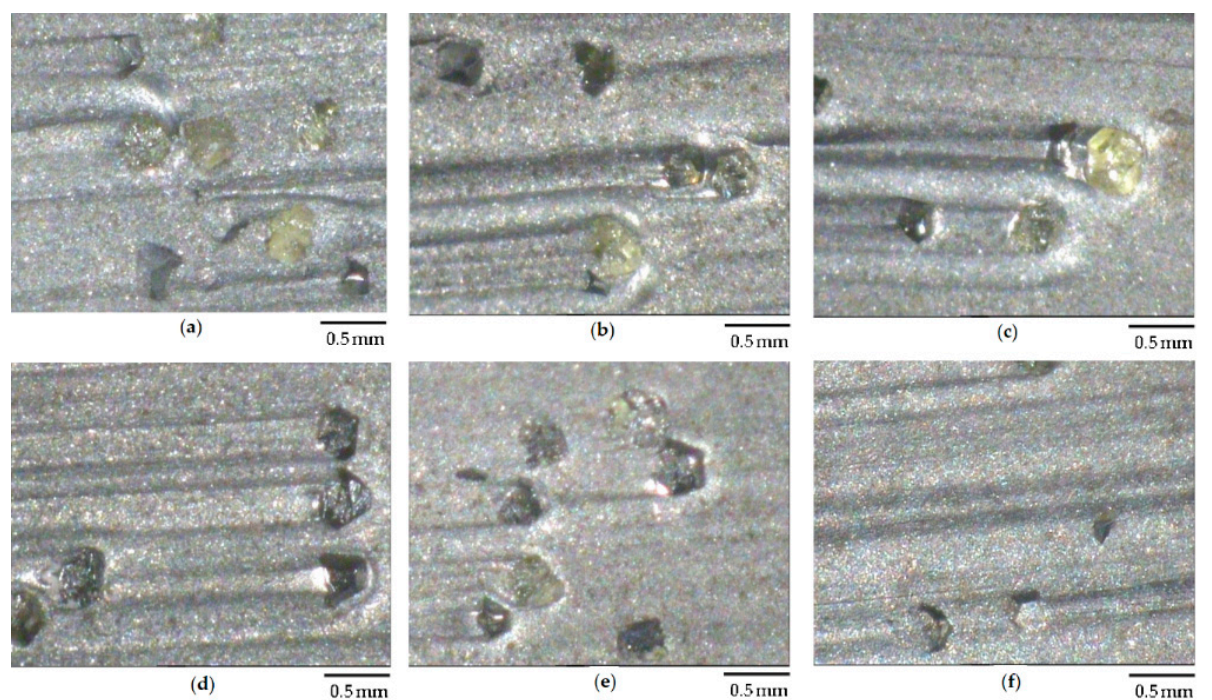

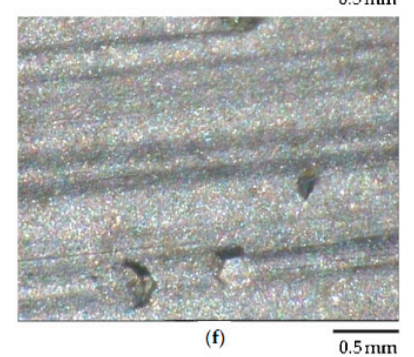

Figure 11. Examples of optical observations of the surface of the segments after the tests: (a-c) Cobalite HDR; (d-f) Next 300.

\section{Conclusions}

First of all, this work demonstrated a methodology to measure several mechanical properties of a series of isolated (i.e., without diamonds) PM matrix alloys in order to compare them. Then, it was necessary to associate those properties with the behaviour of the diamond tools when they were grinding one specific ornamental stone, using specific working parameters.

After characterisation of the metallic binders, those that were considered the most suitable ones were used to produced grinding wheels geometrically equal but different in the type of metallic binder (using powders Cobalite HDR and Next 300). It was then possible to realise that the metallic binder properties had a very important role in the diamond tool performance during the cutting process. Analysing the results, it was shown that the hardest metallic binder (Cobalite HDR) presented higher wear (compared to Next 300), when grinding Azul Alpalhão granite, under the specific working parameters.

The Next 300 metallic binder possessed a great value of toughness when compared to the other binders that were used in this work. Because of that, for grinding this type of granite, the binder Next 300 revealed a better diamond retention capacity, and at the same time showed higher deformation capacity (can absorb more energy prior to rupture). So, the diamond tool made with segments of Next 300 was more efficient (showed a lower wear rate) for the specific grinding process under consideration.

Author Contributions: C.A.A. and P.M.A. methodology, investigation, data curation, original draft preparation; J.C.F. formal analysis and validation; L.G.R. methodology, writing-review and editing; administration and funding acquisition.

Funding: This work was supported by Fundação para a Ciência e a Tecnologia (FCT), Portugal, through IDMEC-Instituto de Engenharia Mecânica (Pólo IST), under LAETA-Associated Laboratory for Energy, Transports and Aeronautics (project grant UID/EMS/50022/2019).

Conflicts of Interest: The authors declare no conflict of interest.

\section{References}

1. Rosa, L.G.; Fernandes, J.C.; Amaral, P.M. A Method for Classification of Stone Materials according to their Abrasiveness. In Proceedings of the EUROTHEN98 Workshop, Athens, Greece, 12-14 January 1998; pp. 338-345.

2. Rosa, L.G. Diamond tool characterisation methodologies: New perspectives for stone processing. In Application of Diamond Technology in the Stone Sector; Chapter 5; OSNET Editions; EUR 20637/4; Carosio, S., Paspaliaris, I., Eds.; European Commission: Brussels, Belgium, 2004; Volume 4, pp. 45-63. 
3. Konstanty, J.S. Applications of powder metallurgy to cutting tools. In Advances in Powder Metallurgy. Properties, Processing and Applications; Chang, I., Zhao, Y., Eds.; Woodhead Publishing: Sawston, UK; Cambridge, UK, 2013; pp. 555-585.

4. Zhao, X.; Duan, L. A review of the diamond retention capacity of metal bond matrices. Metals 2018, 8, 307. [CrossRef]

5. Reis, L.; Amaral, P.M.; Li, B.; de Freitas, M.; Rosa, L.G. Evaluation of the residual stresses due to the sintering process of diamond-metal matrix hot-pressed tools. Theor. Appl. Fract. Mech. 2008, 49, 226-231. [CrossRef]

6. Li, B.; Amaral, P.M.; Reis, L.; Anjinho, C.A.; Rosa, L.G.; de Freitas, M. 3D-modelling of the local plastic deformation and residual stresses of PM diamond-metal matrix composites. Comput. Mater. Sci. 2010, 47, 1023-1030. [CrossRef]

7. Borowiecka-Jamrozek, J.; Lachowski, J. An analysis of the retention of a diamond particle in a metallic matrix after hot pressing. Arch. Foundry Eng. 2017, 17, 17-20. [CrossRef]

8. Borowiecka-Jamrozek, J.; Lachowski, J. The effect of the properties of the metal matrix on the retention of a diamond particle. Metalurgija 2017, 56, 83-86.

9. Xu, J.; Sheikh, A.H.; Xu, C. 3-D Finite element modelling of diamond pull-out failure in impregnateddiamond bits. Diamond Relat. Mater. 2017, 71, 1-12. [CrossRef]

10. Amaral, P.M.; Fernandes, J.C.; Rosa, L.G. Wear mechanisms in materials with granitic textures-Applicability of a lateral crack system model. Wear 2009, 266, 753-764. [CrossRef]

11. Yan, G.; Yue, W.; Meng, D.Z.; Lin, F.; Wu, Z.Y.; Wang, C.B. Wear performances and mechanisms of ultrahard polycrystalline diamond composite material grinded against granite. Int. J. Refract. Met. Hard Mater. 2016, 54, 46-53. [CrossRef]

12. Coelho, A. Avaliação do desgaste em matrizes metálicas usadas em ferramentas diamantadas e sua relação com as propriedades mecânicas. Master's Thesis, Universidade Técnica de Lisboa-Instituto Superior Técnico, Lisbon, Portugal, 2008.

13. Rosa, L.G.; Coelho, A.; Amaral, P.M.; Fernandes, J.C. Test methodology to evaluate the wear performance of PM matrices used in diamond impregnated tools for cutting hard materials. In Powder Metallurgy for Automotive and High Performance Materials in Engineering Industries; Ramakrishnan, P., Ed.; New Age International (P) Ltd.: New Delhi, India, 2012; pp. 186-193.

14. Clark, I.E.; Kamphuis, B.J. Cobalite HDR: A new prealloyed matrix powder for diamond construction tools. IDR. Ind. Diamond Rev. 2002, 62, 177-182.

15. Ugues, D.; Actis Grande, M.; Rosso, M. Study of the relation between hardness, toughness and resistance to wet abrasion in diamond segments. In Proceedings of the Euro PM2003, Valencia, Spain, 20-22 October 2003; pp. 375-383.

16. De Oliveira, H.C.P.; Coelho, A.; Amaral, P.M.; Fernandes, J.C.; Rosa, L.G. Comparison between cobalt and niobium as a matrix component for diamond impregnated tools used for stone cutting. Key Eng. Mater. 2013, 548, 98-105. [CrossRef]

17. Rosa, L.G.; Amaral, P.M.; Anjinho, C.A.; Fernandes, J.C. Evaluation of diamond tool behaviour for cutting stone materials. Ind. Diamond Rev. 2004, 1, 45-50.

18. Rosa, L.G.; Fernandes, J.C.; Anjinho, C.A.; Coelho, A.; Amaral, P.M. Long-term performance of stone-cutting tools. Int. J. Refract. Met. Hard Mater. 2015, 49, 276-282. [CrossRef]

19. Anjinho, C.A. Análise de ferramentas diamantadas utilizadas em corte e desbaste de mármores e granitos. Master's Thesis, Universidade Técnica de Lisboa-Instituto Superior Técnico, Lisbon, Portugal, 2004.

(C) 2019 by the authors. Licensee MDPI, Basel, Switzerland. This article is an open access article distributed under the terms and conditions of the Creative Commons Attribution (CC BY) license (http://creativecommons.org/licenses/by/4.0/). 